\title{
Evaluation of the relationship between the maxillary third molars and pterygomaxillary fissure by cephalometric radiographs
}

\author{
S. Sadry'®i), C.G. Koca² ${ }^{2}$, I. Kaya²® \\ ${ }^{1} D D S / P h D$, Assistant Professor, Department of Orthodontics, Faculty of Dentistry, Istanbul Aydin Universty, Istanbul, \\ Turkey \\ ${ }^{2} \mathrm{DDS} / \mathrm{PhD}$, Assistant Professor, Department of Oral and Maxillofacial Surgery, Faculty of Dentistry, Usak Universty, Usak, \\ Turkey
}

[Received: 11 June 2020; Accepted: 27 July 2020]

Background: The aim of this study is to evaluate the relationship between the third molars which are determined to be closely related to pterygomaxillary fissure (PTM) in cephalometric radiographs.

Materials and methods: The material of this study was panoramic from 200 individuals (101 male, 99 female, mean age $19.02 \pm 1.62)$ with three different skeletal malocclusion in the sagittal direction (class I: 109; class II: 66; class III: 25) and lateral cephalometric radiographs. It was observed that 151 of the patients included in this study had unilateral, 49 bilateral impacted maxillary third molars teeth. Angular and millimetric measurements (SNA ${ }^{\circ}, S N B^{\circ}, A N B^{\circ}$, PTM [Height-x], PTM [Width-y]) were made in accordance with the parameters determined on the lateral cephalometric radiographs of individuals. In this retrospective study, the relation of impaction with PTM evaluated on cephalometric radiographs, whether the impaction was unilateral or bilateral, was investigated in terms of skeletal anomaly. Chi-square test was used for the analysis.

Results: Of the 200 individuals with impacted maxillary third molar, 99 were female and 101 were male. There is no statistical difference between them in terms of unilateral and bilateral impacted third molars ( $p>0.05$ ). Of the 200 patients, 109 patients were class I, 66 patients were class II, and 25 patients were class III. There is no statistical difference between unilateral and bilateral impacted cases in facial skeletal classification ( $p>0.05$ ). According to chi-square test results, the relationship between genders and PTM variable width and height (PTM-x and PTM-y) measurements were not statistically significant ( $p>0.05)$.

Conclusions: The fact that the third molar teeth are impacted bilaterally or unilaterally is not affected by PTM change. (Folia Morphol 2021; 80, 2: 425-431)

Key words: cephalometric radiography, maxillary third molar, pterygomaxillary fissure, panoramic radiograph

Address for correspondence: S. Sadry, Assistant Professor, Istanbul Aydin Universty, Florya, 34295, Istanbul, Turkey, tel: +90212 41130 00-29531 e-mail: sanazsadry@hotmail.com

This article is available in open access under Creative Common Attribution-Non-Commercial-No Derivatives 4.0 International (CC BY-NC-ND 4.0) license, allowing to download articles and share them with others as long as they credit the authors and the publisher, but without permission to change them in any way or use them commercially. 


\section{INTRODUCTION}

Maxillary complex is affected by not only face components but also skull base and neurocranium [4]. The functional matrix hypothesis tries to explain the adaptation of skeletal tissues and organs during modification of craniofacial growth. According to this hypothesis, the two main units are skeletal structure and functional elements. Therefore, in the development of craniofacial skeletal structures, some adaptive responses can be influenced by functional components [16-18]. Functional components refer to soft tissues surrounding skeletal units, organs, and operational volumes that perform a given function $[4,7]$. The interaction between the skeletal unit and functional matrices may also have an effect on the spaces between skeletal units such as the pterygopalatine fossa [11]. The pterygopalatine fossa is a space between the maxilla, palatine, and sphenoid bones $[3,25]$. The pterygomaxillary fissure (PTM), on the other hand, forms the lateral boundary of the pterygopalatine fossa. In clinical terms, the PTM is in an important landmark for orthognathic surgical procedures such as Le Fort I osteotomy, and extraoral and intraoral maxillary nerve blockage $[3,11]$. Furthermore, during surgically assisted rapid maxillary expansion, the PTM and the remaining posterior connection of the maxilla with the pterygoid process region can improve blood circulation and also provide symmetrical openings of the maxillary shelves [26].

With the influence of the development of the maxillary complex, differences in anatomical formations and structures can be observed in the maxillary complex. Especially with the maxillary deficiency, the progression of third molar teeth can also be affected.

The third molars are the teeth to become most frequently impacted. The most common reason for the third molar teeth to become impacted is the fact that they the last teeth to erupt, which leaves them with insufficient space for eruption. Impacted teeth can cause pathologies such as tooth decay, root resorption, pericoronitis, pains of unknown origin, orthodontic and prosthetic problems, infections, odontogenic cysts and tumours $[13,14]$. In cases of inadequate space on the dental arch, tooth eruption can be obstructed by the gingiva, bone or other adjacent teeth.

The relationship between the cranium and various anomalies has been previously studied $[8,10,19]$. The PTM seems to have an effect on both growth and developmental stages of the face. In addition to this knowledge of the PTM morphology also seems to be essential during surgical procedures. Therefore, the aim of this study was to investigate the PTM length and possible correlation between maxillary third molars existence using cephalometric radiographs.

\section{MATERIALS AND METHODS}

The study conducted on the patients who were admitted to Istanbul Aydin University Faculty of Dentistry Department of Orthodontic to undergo orthodontic treatment. Ethical approval was obtained from Istanbul Aydin University Faculty of Dentistry "Ethics Committee on Non-Interventional Clinical Research-Research Not Involving Pharmaceutics and Medical Devices" (Number: B.30.2AYD.0.00.00-50.06.04/67). The present study included 200 patients, 101 males and 99 females, between the ages of 19 and 39 (mean age 24.9), with the indications of impacted third molar dental surgery who were admitted to Istanbul Aydin University Faculty of Dentistry Department of Orthodontics from 2015-2018. The sample size was calculated based on a power analysis and $90 \%$ strength using G * Power Software version 3.1.9.2 (Universität Düsseldorf, Germany) for the sella turcica classification with an alpha error probability of 0.05 . Power analysis showed that 134 samples were absolutely necessary. During the acquisition of lateral cephalometric radiographs, the patient's head was fixed on the cephalostat, and the Frankfort horizontal plane was adjusted parallel to the ground. Radiographs were taken with the central beam perpendicular to the patient's mid-axial plane and the teeth in centric occlusion. It was paid attention to see clearly the PTM. The individuals in the study were classified according to the ANB angle determined on the lateral cephalometric radiograph as class I, class II and class III in the sagittal direction, with the unilateral or bilateral impaction of the maxillary third molar teeth (Table 1). Skeleton classification was done according to ANB angle as shown in Table 1. It was paid attention to see clearly the PTM in lateral cephalometric films (Fig. 1). The width (W), depth (D) and interclenoid (I) determined by Costa et al. [6] with respect to the dimensions of sella turcica on each radiograph are shown in Figure 2. Patients with unilaterally and/or bilaterally impacted teeth, completed bone retention, with no local factors that would cause impaction, and with no missing teeth. The data from the patients 
Table 1. Relationship of impacted molar with gender and facial skeletal classification

\begin{tabular}{llcccc}
\hline & & \multicolumn{3}{c}{ Maxillary third molar teeth } & P \\
\cline { 3 - 4 } & & Unilateral impacted & Bilateral impacted & Total & $0.172 ;$ NS \\
\hline Gender & Female & $80(53.3 \%)$ & $19(38.7 \%)$ & $99(46.2 \%)$ & $101(53.8 \%)$ \\
\multirow{3}{*}{ Facial skeletal classification } & Male & $71(46.6 \%)$ & $30(61.2 \%)$ & $109(47.7 \%)$ & $0.356 ;$ NS \\
& Class I & $81(46.6 \%)$ & $28(50.1 \%)$ & $66(42.8 \%)$ & \\
& Class II & $50(41.6 \%)$ & $16(43.7 \%)$ & $25(9.5 \%)$ & \\
Total & Class III & $20(12.0 \%)$ & $5(6.2 \%)$ & $200(100.0 \%)$ \\
\hline
\end{tabular}

NS - not significant

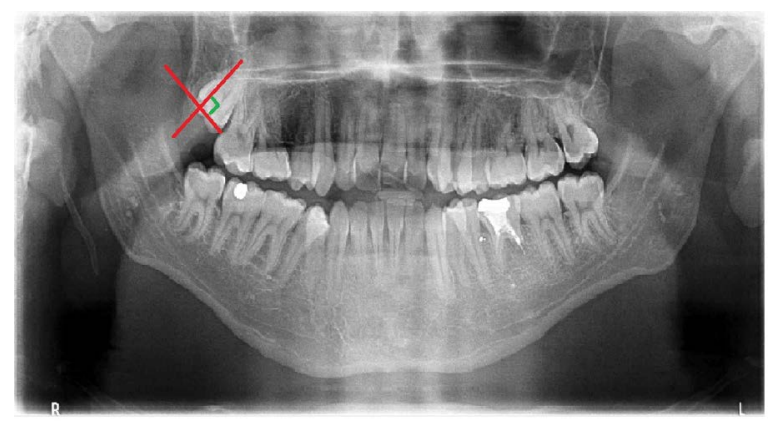

Figure 1. Class III and class $C$ groups according to Archer (1975) classification. In panoramic images, it is seen that two lines intersect at 90 degrees, parallel to the long axis and occlusal plane of the third molar tooth impacted in the maxillary.

under 18 years of age who had suffered a trauma or accident in the head and neck region, undergone previous surgery on the sinus or skull base, and suffer from any syndromes or congenital anomalies (craniocytosis, hemi-facial microstomy) were excluded from the study (Fig. 1). A clear visualisation of the PTM was ensured in lateral cephalometric images. All radiographs were taken using the same cephalometry device (Morita Veraviewpocs Dental X-ray 2D [Type: J. Morita, Kyoto, Japan]) with the Frankfort plane parallel to the ground, teeth in centric occlusion, and lips in resting position. Cephalometric radiographs were evaluated by the same researcher using the NemoCeph NX 9.0 software program (Nemotech, Imaging and Management Solutions, Chatsworth, Madrid, Spain) (Fig. 2). To evaluate the method error, 50 films were redrawn and measured again by the same researcher 2 weeks later. Paired $t$ test was applied between the first and second measurements and no statistically significant difference was found between the two measurements. These results show that our drawings and measurements are repeatable.

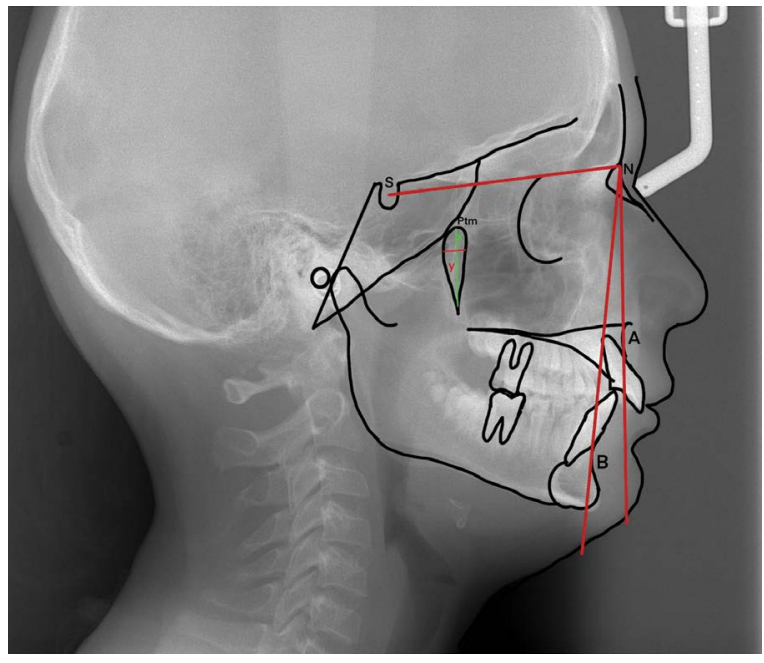

Figure 2. Cephalometric angular measurements used in the research; SNA - the angle between the anterior skull base (S-N plane) and point $A ; S N B-$ it is the angle between the front head base (S-N plane) and point B; ANB — angle between NA and NB lines. Determines the relation of the apical bases of the lower and upper jaw relative to each other. According to Steiner analysis, its normal value is between 0 and 4 degrees; PTM-x [mm] - height of pterygomaxillary fissure; PTM-y [mm] — width of the pterygomaxillary fissure.

\section{Statistical analysis}

The data were evaluated in SPSS 21.0 (Statistical Package for Social Sciences, Chicago, Illinois, USA) statistical package programme. The analysis of the data was evaluated using the $\chi^{2}$ test. The significance level was considered statistically significant for $p<0.05$.

\section{RESULTS}

This study was performed on 249 maxillary third molar teeth in a total of 200 patients, 99 (49.5\%) women and $101(50.5 \%)$ men. Of the 200 patients included in the study, 49 had bilateral and 151 were 
unilateral maxillary third molar teeth. According to the results of $\chi^{2}$ analysis, the relationship between gender and molar variable was not statistically significant $(p>0.05) .53 .3 \%$ of female had unilateral (unilateral) molar, $38.7 \%$ of female had bilateral (bilateral) maxillary molars. $46.6 \%$ of male had unilateral molar and $61.2 \%$ of male had bilateral molar. In both gender categories, unilateral molar status was found higher than bilateral molar status, so gender has no relation with molar status (Tables $1-3$ ).

Since the variables are not normally distributed, the non-parametric test used in the comparison of two independent groups was used in the $\chi^{2}$ test. According to the $\chi^{2}$ test results, no variables were found statistically significant according to the molar status (Table 4). In the comparison of skeletal subgroups in facial skeletal classification, there was no statistically significant difference in the vertical and width distance (PTM-x, PTM-y) between the peak and the lower point of the PTM ( $p>0.05)$ (Table 5). According to this test result, PTM variables did not differ by gender (Table 6).

\section{DISCUSSION}

The third molars are the most frequently impacted teeth. The most common reason of impaction of the third molars is to be last teeth and not enough space to continue. The hard placement of these teeth on the back of the tooth depends on the fact that the conditions of dentition and eruption as well as the distance and direction travelled during riding differ from other teeth. With the increasing need for orthodontic treatment, especially the need for orthodontic surgery, consensus is needed for the relationship of third molar with anatomical structures. This study was performed on lateral cephalographs from untreated patients. Again, in order to reduce errors in anatomical point definition, anatomical points were checked again by the same researcher. Anatomical points used in steiner analysis were marked on the lateral cephalographs obtained and related measurements were made. This analysis includes measurements that define dental and skeletal relationships that are important for orthodontists, and partially for oral and maxillofacial surgeons. The maxillary third molars are not included in the scope of orthodontic theory and complete the process of riding with a completely opposite movement. Impacted teeth; It is a common problem with a prevalence of $18-32 \%$, affecting a large population in the world. In order
Table 2. Relationship of unilateral impacted molar with gender and facial skeletal classification

\begin{tabular}{lcccc}
\hline \multirow{2}{*}{$\begin{array}{l}\text { Facial } \\
\text { skeletal } \\
\text { classifi- } \\
\text { cation }\end{array}$} & $\begin{array}{c}\text { Female } \\
\mathbf{n}(\%)\end{array}$ & $\begin{array}{c}\text { Male } \\
\mathbf{n}(\%)\end{array}$ & $\begin{array}{c}\text { Total } \\
\mathbf{n ~ ( \% )}\end{array}$ & \\
\hline Class I & $28(35.0 \%)$ & $30(42.2 \%)$ & $58(38.4 \%)$ & \\
Class II & $33(41.2 \%)$ & $24(33.8 \%)$ & $57(37.7 \%)$ & \\
Class III & $19(23.7 \%)$ & $17(23.7 \%)$ & $36(23.8 \%)$ & $0.451 ;$ NS \\
Total & $80(100.0 \%)$ & $71(100.0 \%)$ & $129(100.0 \%)$ & \\
\hline
\end{tabular}

$\mathrm{n}$ - number of individuals; NS - not significant

Table 3. Relationship of bilateral impacted molar with gender and facial skeletal classification

\begin{tabular}{lcccc}
\hline \multirow{2}{*}{$\begin{array}{l}\text { Facial } \\
\text { skeletal } \\
\text { classifi- } \\
\text { cation }\end{array}$} & $\begin{array}{c}\text { Female } \\
\mathbf{n}(\%)\end{array}$ & $\begin{array}{c}\text { Male } \\
\mathbf{n ~ ( \% )}\end{array}$ & $\begin{array}{c}\text { Total } \\
\mathbf{n}(\%)\end{array}$ & \\
\hline Class I & $10(52.6 \%)$ & $15(50.0 \%)$ & $25(51.0 \%)$ & \\
Class II & $9(47.3 \%)$ & $12(40.0 \%)$ & $21(42.8 \%)$ & $0.448 ;$ NS \\
Class III & $0(0.0 \%)$ & $3(10.0 \%)$ & $3(6.8 \%)$ & \\
Total & $19(100.0 \%)$ & $30(100.0 \%)$ & $71(100.0 \%)$ & \\
\hline
\end{tabular}

$\mathrm{n}$ - number of individuals; NS - not significant

Table 4. Relationship of impacted molar and pterygomaxillary fissure

\begin{tabular}{lccc}
\hline & $\begin{array}{c}\text { Unilateral impacted } \\
\text { molar - mean } \pm \text { SD }\end{array}$ & $\begin{array}{c}\text { Bilateral impacted } \\
\text { molar - mean } \pm \text { SD }\end{array}$ & P \\
\hline PTM- $x$ & $25.18 \pm 3.24$ & $25.2 \pm 3.2$ & $0.420 ;$ NS \\
PTM-y & $5.22 \pm 1.2$ & $5.15 \pm 1.18$ & $0.445 ;$ NS \\
\hline
\end{tabular}

PTM-x [mm] — height of pterygomaxillary fissure; PTM-y [mm] — width of the pterygomaxillary fissure; SD — standard deviation; NS — not significant

Table 5. Relationship of pterygomaxillary fissure and facial skeletal classification

\begin{tabular}{lccc}
\hline & $\begin{array}{c}\text { PTM-x } \\
\text { - mean } \pm \text { SD }\end{array}$ & $\begin{array}{c}\text { PTM-y } \\
- \text { mean } \pm \text { SD }\end{array}$ & P \\
\hline Class I & $25.64 \pm 3.24$ & $5.18 \pm 1.14$ & $0.420 ;$ NS \\
Class II & $25.55 \pm 3.2$ & $5.1 \pm 1.1$ & $0.330 ;$ NS \\
Class III & $25.42 \pm 3.04$ & $5.22 \pm 1.02$ & $0.433 ;$ NS \\
\hline
\end{tabular}

PTM- $x[\mathrm{~mm}]$ - height of pterygomaxillary fissure; PTM-y $[\mathrm{mm}]$ - width of the pterygomaxillary fissure; SD — standard deviation; NS — not significant

Table 6. Relationship of gender and pterygomaxillary fissure

\begin{tabular}{lccc}
\hline & $\begin{array}{c}\text { Female }(\mathbf{n}=\mathbf{1 0 1}) \\
- \text { mean } \pm \text { SD }\end{array}$ & $\begin{array}{c}\text { Male }(\mathbf{n}=\mathbf{9 9}) \\
- \text { mean } \pm \text { SD }\end{array}$ & $\mathbf{P}$ \\
\hline PTM-x & $25.68 \pm 3.16$ & $25.79 \pm 3.09$ & $0.576 ;$ NS \\
PTM-y & $5.19 \pm 1.03$ & $5.21 \pm 1.02$ & $0.258 ;$ NS \\
\hline
\end{tabular}

PTM-x [mm] — height of pterygomaxillary fissure; PTM-y [mm] — width of the pterygomaxillary fissure; SD — standard deviation; NS — not significant 
to determine the appropriate treatment method of impacted teeth, to prevent complications that may occur during or after treatment, the positions of the impacted teeth in the jaw should be evaluated in detail with their adjacent anatomical structures.

Radiological evaluation plays an important role on the treatment plan [28]. Impacted teeth can cause pathologies such as pericoronitis, cystic lesions, tumours, periapical lesions and resorption in the adjacent tooth. For this reason, third molars must be removed when they are associated with pathological findings or for prophylactic reasons $[2,15,20,21]$. For this reason, it is planned that the maxillary third molars will remain bilaterally or unilaterally, and the relationship between the base length of the maxilla and the anatomical structures will be examined. Therefore, the present study is a unique study that will bring a different perspective to the impaction pattern of the maxillary third molars. Since the known average impaction age of the third molars is 17 to 21 , we set an age limit of 18 and found the mean age to be 24.9 for our study. There was no difference between the genders in our study. Tuğsel et al. [27] did not mention a difference in the distribution of impacted third molars between the genders in parallel with other information in the literature [13, 24]. In the study of Dural et al. [9], the incidence of impacted teeth was found to be higher in female than in male and it was statistically confirmed. According to the results of the $\chi^{2}$ test used in comparing the two independent groups, age and PTM variables did not differ by gender. In the present study, it was observed that in the majority of the impacted maxillary third molars, the teeth were on the border of the PTM and no bone septa were observed between the PTM and third molars. According to this result, the vast majority of these teeth may be related to the development of the base length of the maxilla and it is likely that any complications occur during tooth extraction. As a result of cephalometric analysis in the present study, it is thought that the increase in anterior face height and PTM length measurement in female is characterised by an increase in the maxilla skeletal unit. In their three-dimensional cone-beam computed tomography studies, Costa et al. [6] recorded findings indicating no correlation between the anterior face height and maxillary posterior vertical alveoli, and thereby, PTM, which is in contradiction with our findings.
On the other hand, Rothstein and Yoon-Tarlie [23] found a statistically positive relationship between the anterior facial heights and the maxilla posterior heights of individuals in the age group of 10 and 12 , similar to the results, in their longitudinal study. The reason for this is thought to be population differences. In the retrospective evaluation performed in our study, the relationship between the variables was determined by considering the differences in the lateral projection with anatomical structures in PTM, which was not previously evaluated in English or foreign literature. In the present study, no statistical difference was found in the evaluation of PTM variable according to gender, localisation and the condition of the third molars $(p>0.05)$. Rothstein and Yoon-Tarlie [23] determined the length of the PTM by measuring the distance from the deepest point of the buccal sulcus to the peak of the fissure. To know the difference in measurements between PTM lengths; in anaesthesia to be performed in the region, it is thought that paying attention to the penetration depth of the needle according to localisation is important in terms of ophthalmic or intracranial complications that may occur due to providing sufficient anaesthesia and advancing deeper than necessary. In the present study, a negative correlation was found between age and PTM variable. There was no statistically significant difference in terms of PTM variable in patients according to age groups ( $p>0.05$ ). Although the age progression causes changes in the fissure area, it suggests that the fissure does not cause macro changes in the overall morphology. Considering the results obtained by Albert et al. [1] in their studies, it was observed that the growth in both soft and hard tissues continued after adolescence. As a result of the reshaping of the alveolar bone in the craniofacial complex, PTM, which is located behind the tuber region, is also thought to be affected by these changes. However, as mentioned earlier, it is thought that it will not be appropriate to use this point orthodontically as a fixed reference $[5,12,22]$.

\section{CONCLUSIONS}

In groups formed according to unilaterally or bilaterally impacted maxillary third molars, anatomical structures were found not to affect the impacted teeth rather than the significant differences. Regarding PTM in both genders, unilateral and bilateral impacted third molars were not found to differ 
significantly between groups. It was also found that there were no significant differences between the groups of skeletal anomalies and embedded upper third molars with respect to PTM. It is thought that further studies should be supported by a larger number of patients.

\section{Acknowledgements}

The authors would like to thank Elif Eren for her valuable help with the cephalometric tracing.

\section{Funding}

The study was financially supported by the researcher and authors.

\section{REFERENCES}

1. Albert AM, Ricanek K, Patterson E. A review of the literature on the aging adult skull and face: implications for forensic science research and applications. Forensic Sci Int. 2007; 172(1): 1-9, doi: 10.1016/j.forsciint.2007.03.015, indexed in Pubmed: 17434276.

2. Alling JJ, Helfrick JF, Alling RD. Impacted teeth. WB Saunders, Philadelphia 1993.

3. Breeze J, Verea Linares C, Stockton P. Is an osteotome necessary for pterygomaxillary dysjunction or dysjunction through the tuberosity during Le Fort I osteotomy? A systematic review. Br J Oral Maxillofac Surg. 2016; 54(3): 248-252, doi: 10.1016/j.bjoms.2015.11.014, indexed in Pubmed: 26687554.

4. Carlson D. Theories of craniofacial growth in the postgenomic era. Semin Orthod. 2005; 11(4): 172-183, doi: 10.1053/j.sodo.2005.07.002.

5. Cevidanes LHS, Franco AA, Gerig G, et al. Comparison of relative mandibular growth vectors with high-resolution 3-dimensional imaging. Am J Orthod Dentofacial Orthop. 2005; 128(1): 27-34, doi: 10.1016/j.ajodo.2004.03.033, indexed in Pubmed: 16027622.

6. Costa HN, Slavicek R, Sato S. A computerized tomography study of the morphological interrelationship between the temporal bones and the craniofacial complex. J Anat. 2012; 220(6): 544-554, doi: 10.1111/j.14697580.2012.01499.x, indexed in Pubmed: 22458595.

7. Dargaud J, Cotton F, Buttin R, et al. [The maxillary sinus: evolution and function in aging]. Morphologie. 2003; 87(276): 17-22, indexed in Pubmed: 12793110.

8. Dibbets JM. Morphological associations between the Angle classes. Eur J Orthod. 1996; 18(2): 111-118, doi: 10.1093/ejo/18.2.111, indexed in Pubmed: 8670923.

9. Dural S, Avcı N, Karabıyıkoğlu T. Gömük dişlerin görülme sıklığı, çenelere göre dağılımları ve gömülü kalma nedenleri. Sağ Bil Arş Derg. 1996; 7: 127-133.

10. Hwang SeH, Seo JH, Joo YH, et al. An anatomic study using three-dimensional reconstruction for pterygopalatine fossa infiltration via the greater palatine canal. Clin Anat. 2011; 24(5): 576-582, doi: 10.1002/ca.21134, indexed in Pubmed: 21400608.
11. Icen M, Orhan K. Cone-beam computed tomography evaluation of the pterygomaxillary fissure and pterygopalatine fossa using 3D rendering programs. Surg Radiol Anat. 2019; 41(5): 513-522, doi: 10.1007/s00276-019-02201-2, indexed in Pubmed: 30725218.

12. Iseri $H$, Solow B. Average surface remodeling of the maxillary base and the orbital floor in female subjects from 8 to 25 years. An implant study. Am J Orthod Dentofacial Orthop. 1995; 107(1): 48-57, doi: 10.1016/ s0889-5406(95)70156-7, indexed in Pubmed: 7817961.

13. Kruger E, Thomson WM, Konthasinghe P. Third molar outcomes from age 18 to 26: findings from a population-based New Zealand longitudinal study. Oral Surg Oral Med Oral Pathol Oral Radiol Endod. 2001; 92(2): 150-155, doi: 10.1067/moe.2001.115461, indexed in Pubmed: 11505260.

14. Lim AA, Wong CW, Allen JC. Maxillary third molar: patterns of impaction and their relation to oroantral perforation. J Oral Maxillofac Surg. 2012; 70(5): 1035-1039, doi: 10.1016/j.joms.2012.01.032, indexed in Pubmed: 22494509.

15. Mollaoglu N, Cetiner S, Güngör K. Patterns of third molar impaction in a group of volunteers in Turkey. Clin Oral Investig. 2002; 6(2): 109-113, doi: 10.1007/s00784-0010144-1, indexed in Pubmed: 12166710.

16. Moss ML, Salentijn L. The capsular matrix. Am J Orthod. 1969; 56(5): 474-490, doi: 10.1016/0002-9416(69)90209-7, indexed in Pubmed: 5261161.

17. Moss ML. The functional matrix hypothesis revisited. 1. The role of mechanotransduction. Am J Orthod Dentofacial Orthop. 1997; 112(1): 8-11, doi: 10.1016/s08895406(97)70267-1, indexed in Pubmed: 9228835.

18. Moss ML. The functional matrix hypothesis revisited. 2 . The role of an osseous connected cellular network. Am J Orthod Dentofacial Orthop. 1997; 112(2): 221-226, doi: 10.1016/ s0889-5406(97)70249-x, indexed in Pubmed: 9267235.

19. Oz U, Orhan K, Aksoy S, et al. Association between pterygoid hamulus length and apnea hypopnea index in patients with obstructive sleep apnea: a combined three-dimensional cone beam computed tomography and polysomnographic study. Oral Surg Oral Med Oral Pathol Oral Radiol. 2016; 121(3): 330-339, doi: 10.1016/j. oooo.2015.10.032, indexed in Pubmed: 26776720.

20. Ozeç I, Hergüner Siso S, Taşdemir U, et al. Prevalence and factors affecting the formation of second molar distal caries in a Turkish population. Int J Oral Maxillofac Surg. 2009; 38(12): 1279-1282, doi: 10.1016/j.ijom.2009.07.007, indexed in Pubmed: 19665355.

21. Peterson L, Ellis II, Hupp JR. Contemporary oral and maxillofacial surgery. 3rd ed. Mosby, St. Louis 1998: 215-248.

22. Piva LM, Brito HHA, Leite HR, et al. Effects of cervical headgear and fixed appliances on the space available for maxillary second molars. Am J Orthod Dentofacial Orthop. 2005; 128(3): 366-371, doi: 10.1016/j.ajodo.2004.04.032, indexed in Pubmed: 16168333.

23. Rothstein T, Yoon-Tarlie C. Dental and facial skeletal characteristics and growth of males and females with class II, division 1 malocclusion between the ages of 10 and 14 (revisited) - part I: characteristics of size, form, and 
position. Am J Orthod Dentofacial Orthop. 2000; 117(3): 320-332, doi: 10.1016/s0889-5406(00)70237-x, indexed in Pubmed: 10715092.

24. Schersten E, Lysell L, Rohlin M. Prevalence of impaced thırd:molars in dental students. Swed Dent J. 1989; 13: 7-13.

25. Tashi S, Purohit BS, Becker M, et al. The pterygopalatine fossa: imaging anatomy, communications, and pathology revisited. Insights Imaging. 2016; 7(4): 589-599, doi: 10.1007/ s13244-016-0498-1, indexed in Pubmed: 27230518.
26. Tausche E, Deeb W, Hansen L, et al. CT analysis of nasal volume changes after surgically-assisted rapid maxillary expansion. J Orofac Orthop. 2009; 70(4): 306-317, doi: 10.1007/s00056-009-9910-5, indexed in Pubmed: 19649578.

27. Tuğsel Z, Kandemir S, Küçüker F. Üniversite öğrencilerinde üçüncü molarların gömüklülük durumlarının değerlendirilmesi, Cumhuriyet Üniv. Dişhek Fak Der. 2001; 4: 102-105.

28. Türker M, Yücetaş Ş. Ağız Diş Çene Hastalıkları ve Cerrahisi. 3rd ed. Özyurt 2004. 